A R T I G O

\title{
LITERATURA ANTIMORDAÇA. ESCRITORAS E ESCRITAS SILENCIADAS DURANTE O FRANQUISMO. UM ESTUDO PELA PERSPECTIVA DE GÊNERO*
}

\author{
Anti-gag literature. Women writers and writings silenced during \\ francoism. A study from a gender perspective
}

Literatura antimordaza. Escritoras y escritos silenciados durante el franquismo. Un estudio desde una perspectiva de género

\author{
SARA MARTÍN GUTIÉRREZ ${ }^{\text {*** }}$ \\ GABRIELA DE LIMA GRECCO ${ }^{\mathrm{II} * * *}$
}

DOI: http://dx.doi.org/10.1590/S2178-14942020000200006

\footnotetext{
*Este texto faz parte de pesquisa financiada pela Comunidade de Madri, no âmbito das Ayudas destinadas a la Atracción de Talento Investigador e do Projeto de I+D para Jovens Pesquisadores da Universidade Autônoma de Madri, denominado Las relaciones de las dictaduras europeas y latinoamericanas en clave transnacional: entendimiento, rivalidades y conexiones con los Estados democráticos - 1930's 1980's (Referencia SI1/PJI/2019-00257). 0 artigo foi elaborado no âmbito do Programa de Pós-Doutorado em Ciências Humanas e Sociais da Faculdade de Filosofia e Letras da Universidade de Buenos Aires, com financiamento de bolsa interna de pós-doutorado do Consejo Nacional de Investigaciones Científicas y Técnicas (CONICET). Agradecemos o excelente trabalho de tradução de Gabrielle Carvalho Lafin.

Universidad de Buenos Aires, Buenos Aires, Argentina.

**Investigadora del Programa Postdoctoral en Ciencias Humanas y Sociales de la Facultad de Filosofía y Letras de la Universidad de Buenos Aires (sarmar02@ucm.es).

(D) https://orcid.org/0000-0002-2064-8301

"Universidad Autónoma de Madrid, Madrid, Espanha.

*** Investigadora y docente del Departamento de Historia Contemporánea de la Universidad Autónoma de Madrid (gabrielalimagrecco@gmail.com).

(D) http://orcid.org/0000-0002-7137-5251
}

Artigo recebido em 25 de dezembro de 2019 e aprovado para publicação em 12 de março de 2020. 


\title{
RESUMO
}

Este artigo explora as ações do poder ditatorial no campo da censura literária durante o regime franquista nos anos de 1940 e 1950 mediante distintos "expedientes de censura". 0 estudo aprofunda-se na questão do controle vigilante e sua legislação censora, ao mesmo tempo em que investiga os espaços de resistência que 0 coletivo de escritoras encontrou para que suas obras pudessem ser publicadas, averiguando as estratégias que as escritoras empregaram para evitar a temida caneta vermelha de seus vigilantes. Além disso, apresenta-se o modo como as escritoras sofreram com as ferrenhas políticas de gênero que limitavam suas ações à esfera privada.

PALAVRAS-CHAVE: Censura; Franquismo; Estudos de gênero; Literatura; história das mulheres.

\begin{abstract}
This article explores the actions of the dictatorial power in the field of literary censorship during the Franco regime in the forties and fifties through different "censorship means". His study delves into the issue of vigilant control and its censoring legislation while exploring the spaces of resistance that the collective of writers found so that their works could be published. In this way, the strategies that the writers used to avoid the dreaded red pen of their vigilantes are explored. This article, moreover, presents how writers have suffered from the strong gendered politics that limited their actions to the private sphere.
\end{abstract}

KEYWORDS: Censorship; Francoism; Gender studies; Literature; Women history.

\section{RESUMEN}

Este artículo explora las acciones del poder dictatorial en el campo de la censura literaria durante el régimen franquista en los años cuarenta y cincuenta a través de diferentes "dispositivos de censura". Este estudio profundiza en el tema del control vigilante y su legislación de censura mientras explora los espacios de resistencia que el colectivo de escritores encontró para que sus trabajos pudieran publicarse. De esta manera, se exploran las estrategias que los escritores usaron para evitar la temida pluma roja de sus vigilantes. Este artículo, además, presenta cómo los escritores han sufrido la fuerte política de género que limitó sus acciones a la esfera privada.

PALABRAS ClaVE: Censura; Franquismo; Estudios de género; Literatura; Historia de las mujeres. 


\section{INTRODUÇÃO}

Já estava cansada de viver às margens da vida.

Carolina Maria de Jesus, 2007: 184.

história da falta de liberdades de expressão na Espanha franquista reside em uma série
de acontecimentos sociais, políticos, culturais, ideológicos e de gênero no período de ascensão das direitas e ultradireitas no âmbito internacional. 0 fim da Guerra Civil Espanhola representou uma profunda ruptura no que concerne ao processo ascendente de democratização cultural exercido durante o período republicano. Assim, "la cultura, que brillantemente se consolidó durante la Segunda República, aglutinadora de las corrientes liberales y del 98, caracterizada por su laicismo y tolerancia, fue segada de forma abrupta por la dictadura" (Nicolás Marín, 2005: 172). Com a derrota da República, abriu-se uma nova etapa na cultura espanhola iluminada por ideias como hierarquia, disciplina e compromisso. 0 trauma que sofreu a cultura espanhola - com o encerramento da Idade da Prata, que havia se estendido durante o primeiro quarto do século XX — representou uma concepção do saber afastado da tradição liberal. Com o triunfo da facção rebelde, abriu-se um grande parêntese de negação da liberdade da palavra escrita na Espanha, embora, como bem afirmou José-Carlos Mainer, enganem-se os que defendem a inexistência de sinais de vida intelectual e de um labirinto sem saída nem evolução alguma sob o franquismo. A literatura sobreviveu, sempre sobrevive (Mainer, 2005: 27).

Muitos dos avanços legais em relação à busca pela diminuição das desigualdades sexuais do período republicano foram alcançados em virtude da pressão das próprias mulheres, mas esses avanços foram anulados com a chegada do general Franco ao poder e de suas "famílias", especialmente a católica. Nesse contexto de pós-guerra, a população feminina foi submetida a sérias restrições políticas, culturais, laborais, econômicas e sociais, contidas nas novas políticas estatais. No âmbito cultural-literário, diversas escritoras tentaram criar suas obras, apesar da forte censura e da autocensura imposta pela caneta vermelha. No entanto, apesar de sua frutífera produção e da grande qualidade de suas obras, muitas escritoras, como Carmen Kurtz, não ingressaram no cânone literário - a explicação concedida pela teórica Capdevila-Argüelles (2017) é que o cânone é um território eminentemente patriarcal. A não existência das mulheres na arena pública é o resultado de uma ordem patriarcal que é, em si mesmo, uma ordem simbólica. Uma ordem que preserva e reforça a dicotomia entre público/privado, racional/irracional e, claro está, homem/mulher. Nessa lógica dialética, a tentativa de desautorizar a autoria feminina foi um processo cumulativo; assim, conceitual e 
materialmente, foram excluídas da produção de conhecimento, do patrimônio cultural de seus países, e de construir novos sentidos para a realidade e desenvolver uma tradição linguística e literária (Spender, 1982). Foram, portanto, excluídas do sentido de autoria: mulher escritora foi transformado em um oximoro. Por isso, não é possível compreender as razões e os processos que contribuem para o silenciamento de certas autoras sem uma análise pela perspectiva de gênero e interseccional. É imprescindível confrontar a construção de uma memória desigual e dar voz às diversas gerações de escritoras esquecidas e que atualmente não fazem parte da memória e do patrimônio cultural da Espanha.

Quando Roland Barthes decretou em 1968 a morte do autor, sua afirmação resultou problemática para as mulheres ao invalidá-las também como autoras; uma autoridade frágil e a duras penas construída e recentemente reconhecida (Pérez Fontdevila e Torras Francès, 2019: 11). Está claro, portanto, que o cânone literário, baseado em princípios patriarcais, deve ser revisado e atualizado para que se incluam os nomes de mulheres marginalizadas ainda nos dias atuais (Jaime de Pablos, 2018:1). Como argumenta Mikhail Lotman (1993), a canonização está ligada ao devir histórico e, nesse sentido, devem ser considerados os valores, a cultura, os princípios e os preconceitos predominantes de uma época. A entrada de textos na categoria de clássicos não é uma mera questão de valor estético (Said, 2005): o cânone, em realidade, contribui para a formação de relatos de consenso (falocêntricos, heteronormativos e brancocêntricos). Um grupo social, portanto, só existe na medida em que é reconhecido e revelado em uma tradição histórica ou literária (Bourdieu, 2010). Por isso, a construção dos "clássicos" literários implica a eliminação de certos textos, e, em uma sociedade como a franquista, cuja tradição narrativa foi predominantemente falocêntrica, as escritoras sofreram um processo de invisibilização tendo em conta a condição de serem mulheres, mas também pelo caráter socioeconômico, racial e sexual.

Como observou Dale Spender (1982: 62), com o silêncio forçado das mulheres, qualquer alternativa possível em relação à visão masculina hegemônica (e, portanto, única e parcial) do mundo foi excluída, o que a consolidou como a única possível. Dentro dos limites dessa realidade única, foi plausível aceitar a existência de uma única "verdade" e uma única forma "objetiva" de aproximar-se a ela. Mary Daly (1978) referiu-se a esse monopólio de produção de significados e realidades pelos homens como monodimensional. Assim, as mulheres facilmente foram e são excluídas dos relatos historiográficos por "falta de documentação", como se essa constatação fosse algo meramente objetivo. Existe uma suposição de que os arquivos e acervos documentais são neutros e a-históricos. Os arquivos, no entanto, frequentemente invisibilizam a história das mulheres, pois os documentos sobre elas encontrados muitas vezes estão dispostos de maneira dispersa e fragmentada. Os arquivos oficiais aca- 
bam, portanto, por dar voz à "oficialidade": um espaço de poder marcadamente masculino. É um lugar em que tradicionalmente as vozes femininas estão sub-representadas. A literatura, nesse caso, pode ser um caminho muito válido para examinar o contexto dessas escritoras, descobrir sua capacidade de atuação, sua visão de mundo, seu poder (ainda que limitado), assim como a influência ou a resistência às normas de gênero de uma época. A historiadora Nupur Chaudhuri (2010: 21) denomina os romances ou poesias de mulheres escritoras como um arquivo alternativo: um fragmento de material coerente, localizado fora dos repositórios de fontes primárias convencionais.

Trabalhar em arquivos apresenta ao/à historiador/a diversos indícios de dominação (implícitos e explícitos), entre eles o controle da palavra escrita (Vasallo, De Paz-Trueba e Caldo, 2016). Para investigar a respeito de algumas escritoras sob o regime de Francisco Franco, a presente pesquisa não apenas fez uso de suas obras (como arquivo alternativo), mas também dos relatórios de censura do Arquivo General de la Administración (AGA) situado na cidade de Alcalá de Henares, Comunidade de Madri, Espanha - , no qual se conservam as principais fontes documentais deste trabalho e que são, sem dúvida, imprescindíveis para o estudo da censura e das políticas oficiais do livro durante o franquismo. Encontrar os rastros de escritoras nos arquivos de censura foi, sem dúvida, um desafio. Não obstante, ainda que os documentos expedidos pelos censores - os expedientes de censura - tenham sido produzidos por instituições dominadas por homens, ao mesmo tempo estes podem revelar subtextos sobre os preconceitos masculinos, as normas prescritas de gênero e também a ação dessas mulheres. Está claro que muitos dos textos analisados neste trabalho não se tornaram clássicos da literatura espanhola. No entanto, essas mulheres foram escritoras brilhantes, além de precursoras do feminismo, com ideias muitas vezes visionárias para o período histórico correspondente. Assim, essas mulheres - e seus escritos — sempre estiveram presentes. 0 silêncio nem sempre significa a ausência.

\section{MULHERES SOB O FRANQUISMO}

o dia 18 de julho de 1936, após um frustrado golpe de Estado encabeçado pelo ge-
neral Francisco Franco, iniciou-se a Guerra Civil Espanhola (1936-1939) e criaram-se as primeiras condições de controle político, cultural, sexual e de gênero na zona em que a facção sublevada ia conquistando poder territorial e político. 0 regime de Franco oficializou-se após a derrota republicana e consolidou-se progressivamente mediante a promulgação de distintas políticas ditatoriais com o término da guerra em abril de 1939. Nesse contexto, a situação das mulheres ofereceu um panorama desolador e significou, para muitas delas, uma condenação ligada à repressão, ao exílio, ao silêncio e à censura. A população feminina foi 
submetida a sérias restrições nos âmbitos político, cultural, laboral, econômico e social contidas nas políticas estatais de gênero. Na Espanha dos anos de 1940, difundiu-se um modelo de família baseado em elementos procedentes da cultura católica e da política falangista (por intermédio da Seção Feminina da Falange Espanhola)' ${ }^{1}$, sementes legitimadoras do novo regime (Blasco Herranz, 2018; Cenarro, 2006). Os discursos teóricos acerca dos modelos de feminilidade e masculinidade reconhecidos pela ditadura de Franco implicaram a transição do modelo feminino republicano anterior à guerra a um arquétipo baseado na domesticidade e focado na maternidade. Esse discurso, no entanto, entraria em numerosas contradições com a vida diária que a maioria das espanholas experienciava, especialmente aquelas pertencentes às classes mais baixas da população (Alía Miranda et al., 2017: 221). Diante disso, muitas mulheres organizaram resistências, pois nem todas assumiram os postulados de gênero da mesma maneira nem reagiram de maneira homogênea (De Dios Fernández, 2014: 24). Em muitas ocasiões, a experiência coletiva das mulheres, para além das paredes do lar, evidenciou que a suposta separação entre esfera pública e privada era muito mais complexa e difusa.

Após o fim da guerra, a ditadura do general Francisco Franco se esforçaria em anular todos os registros legislativos e de emancipação feminista da etapa anterior, o que proclamou o papel subordinado das mulheres. A consolidação do regime de Franco pressupôs a (re) apropriação de um discurso de gênero hegemônico destinado à educação e ao cuidado da família, relegando as mulheres, mediante uma série de políticas de gênero, ao confinamento privado (Amador e Ruiz Franco, 2007; Arce Pinedo, 2016; Di Febo, 2006; Di Febo e Saba, 1986; Enders e Radcliff, 1998; Prieto Borrego, 2010; Ruiz Franco, 2007). Assim, o franquismo reforçou a ideia da supremacia masculina recorrendo à discriminação legal e às restrições laborais/trabalhistas, entre outras políticas (Ortiz Heras, 2006). Em contrapartida, recuperou-se o modelo de feminilidade que encontrava sérias reminiscências nos arquétipos dos séculos XIX e XX, próprios das culturas políticas de oposição ao liberalismo (Arce Pinedo, 2016).

A defesa da família e do matrimônio heterossexual cristão levou a hierarquia eclesiástica a unir esforços com o regime para impor um modelo feminino comum. No entanto, essa concepção maternal foi assumida para além de suas sobreposições privadas, como uma responsabilidade política na divulgação de novos valores (Blasco Herranz, 2014: 55). De sua parte, a Igreja Católica, como instituição social onipresente e com importante função político-cultural, exerceu papel decisivo no aprofundamento da divisão sexual e da consolidação de valores tradicionais lançando mão de discursos e de representações culturais de gênero. Estado e Igreja atuaram de forma conjunta em relação às mulheres, reforçando seu papel de mãe e esposa, transmissora da ideologia do Novo Estado (Cabrero, 2006: 66). A religião católica teve um papel relevante na configuração do novo status feminino, em virtude do apostola- 
do leigo e dos trabalhos de assistencialismo impulsionados por religiosos e religiosas e pela ação política das mulheres de organizações católicas (Blasco Herranz, 2003; Martín Gutiérrez, 2017; Nicolás Marín e López García, 1982).

A historiadora espanhola Inmaculada Blasco Herranz (2010, 2000), no entanto, destaca a importância de se observar para além da submissão e relativizar a eficácia dos discursos de gênero da época, a fim de não aceitar como dado inquestionável a ausência de autonomia, de consciência e de capacidade de ação das mulheres sob o regime franquista. 0 historiador Toni Morant i Ariño (2012: 113) reforça tal ideia ao destacar que a atuação prática de muitas mulheres, como as falangistas, questiona a existência de uma completa submissão, renegociando e reinterpretando os discursos oficiais de feminilidade. 0 conceito de gênero, assim, pode ser visto como um sistema de símbolos e significados estruturantes e estruturados de práticas e experiências socioculturais (Yanagisako, 1987). De acordo com essa abordagem, podemos analisar a ação das falangistas, das católicas ou de outras mulheres na construção de gênero dominante, mas também seu papel para negociar de acordo com os limites sociais, políticos e culturais da sociedade franquista. Por isso, parece-nos importante destacar identidades femininas muito mais dinâmicas por sua ação política e matizar os modelos de submissão impostos pelas hierarquias do regime, já que sua capacidade de ação nos obriga a pensar precisamente em uma projeção e influência na esfera pública. Com esse propósito, analisaremos nas próximas páginas o papel das escritoras sob um regime censor, com uma gama bastante diversificada de escritoras espanholas, entre elas algumas que conseguiram manter o reconhecimento no mundo das letras que tiveram durante as décadas anteriores, como foi o caso de Concha Espina (1869-1955). Espina já era uma escritora consagrada no cenário internacional desde décadas anteriores, e a sua condição de católica e solidária com o regime de Franco a impediria de sofrer as perseguições políticas que, no entanto, tiveram que enfrentar tantas outras escritoras coetâneas.

\section{A CENSURA FRANQUISTA}

queles que se aventuraram pela escrita no imediato pós-guerra espanhol se depararam a dura censura franquista que havia se instalado no país após o golpe militar de
com 18 de julho de 1936. Cárcere, silêncio ou exílio foram as consequências da censura imposta na Espanha. Já na declaração de guerra havia sido incluída a censura prévia que dava fim à liberdade de imprensa anunciada em 1931, durante a Segunda República Espanhola. Desde outubro de 1936, a recém-criada Junta Técnica de Estado possuía pleno poder para exercer a censura literária. Transcorridos já quase dois anos desde a Guerra Civil Espanhola, foi promulgada uma nova lei, obra do filofascista Ramón Serrano Suñer, então ministro do Interior, que 
colocava a imprensa a serviço do Estado e sob o controle do Partido Único fascista, a Falange Espanhola. A lei de 22 de abril de 1938 estabeleceu a censura prévia, que mereceu a definição, segundo Elisa Chuliá (1997: 145), de mais restritiva da história espanhola. A censura prévia consistia na obrigação de que todo e qualquer tipo de texto passasse pelas mãos de um censor antes de ser entregue para publicação.

É possível entender esse procedimento como o caminho que um texto tem de percorrer para chegar a sua publicação em um sistema complexo de censura prévia. No entanto, durante o franquismo, o processo censor foi precedido por um fenômeno generalizado: a autocensura. 0 maior êxito de um Estado autoritário se dá pela mutilação de uma obra pelo próprio autor, quem, a cada palavra escrita, sente em sua mente a ação da tesoura da censura. A autocensura acaba por facilitar o trabalho dos censores, que apenas têm de completá-la. 0 fato de que os escritores e, especialmente, as escritoras tivessem de incorporar em seu interior o próprio censor, em um processo esquizofrênico de negação de si mesmos e de sua imaginação, outorgou à autocensura um peso talvez mais importante sobre a criação literária que a própria censura. A maioria das escritoras, e também dos escritores, foi obrigada a submeter-se à autocensura, como um mecanismo de antecipação daquilo que o censor não iria permitir. A autocensura, portanto, levou a uma privação do controle do escritor sobre sua obra, pois esta terminava sendo, em última análise, o que o censor considerava que tinha de ser escrito (Larraz, 2014: 32).

Depois da autocensura, a primeira etapa do processo censor ipsis litteris se iniciava quando o editor ou seu representante depositava cinco exemplares de uma obra no Serviço de Censura da sede da Vice-Secretaria de Educação Popular ou em alguma de suas delegações provinciais. Em seguida, no caso de não haver inconvenientes, um ou mais censores (em sua quase maioria absoluta, homens) liam e examinavam a obra. Depois dessa análise, os censores entregavam um formulário ao chefe de Censura. Nesse documento, constavam a avaliação, as páginas nas quais se encontravam os trechos censurados (caso houvesse) e a resposta a um esquema de perguntas. À continuação, confeccionava-se uma folha de censura, um documento que valia como permissão ou proibição para a impressão da obra e como banco de dados, servindo como registro que revelava os antecedentes de autores e editores (Grecco, 2017: 200). Quando o chefe de Censura recebia o relatório, encarregava-se de autorizar ou negar a publicação, decretando em cada caso uma cédula na qual constava o julgamento oficial da obra (Grecco, 2014). Tal avaliação deveria constar na primeira página de cada exemplar; caso contrário, a obra era considerada clandestina.

Além disso, a Igreja Católica realizou um trabalho de censura tanto dentro quanto fora dos aparatos estatais. A Igreja, portanto, tentou limitar e endurecer ainda mais a censura oficial por meio de guias bibliográficos para "orientar" a leitura da população e limitar 
a venda e a circulação de obras que considerava "dissolventes". Esses guias bibliográficos eram elaborados pelas Mujeres de la Acción Católica², tendo elas, por conseguinte, uma ação censora paraoficial (Urbán, 1979). Essas listas circularam nos boletins e nas publicações dos diferentes movimentos da Ação Católica em ambos os lados do Atlântico (McGee Deutsch, 1999). Portanto, é necessário situar a Igreja Católica como agente de moralidade e controle social em nível transnacional, uma vez que atravessou numerosas realidades nacionais e processos histórico-sociais diferentes (Pérez del Puerto, 2015).

\section{ESCRITORAS CENSURADAS}

lei de 22 de abril de 1938 significou um período obscuro para os escritores que per-
ceberam como o franquismo censurou, amputou e impediu a publicação ou a circulação de muitas obras com o pretexto de salvaguardar os valores pátrios, de tradição católica, e eliminar as obras "dissolventes". Nesse contexto, recaíram dois tipos de censura sobre as escritoras: uma censura específica de gênero e outra institucional, por meio da censura prévia. Muitas autoras evitaram - em um claro exercício de autocensura, consciente ou inconsciente — os temas mais controversos e suscetíveis para que suas obras pudessem ser publicadas. Além disso, muitas delas recorreram ao uso de pseudônimos como uma forma de disfarce e ocultação de sua identidade. Diversas autoras fizeram uso desse recurso com 0 objetivo de manter uma privacidade que temiam perder. Segundo a historiadora Carmen de la Guardia (2007: 1), "utilizaron seudónimos como único camino de generar escritura [...]: su pasión por la escritura fue mucho más importante que su deseo de reconocimiento como autoras". Mercedes Fórmica (Elena Puerto), Mercedes Ballesteros (Silvia Visconti), Ángeles Villarta Tuñón (Arcángeles Miranda), María Teresa Martín Iglesia (Cristina Luján), María Josefa Fornovi Martínez (Chiampos) e Sara Barranco Soro (Sarah Demaris) foram algumas das escritoras que decidiram empregar essa estratégia. Outras, como Carmen Laforet e Rosa María Cajal, utilizaram o próprio nome e acabaram sofrendo com a exposição. Vivenciaram, assim, períodos de seca literária, envoltas pelo peso da fama e de sua excessiva timidez (Marín-Marín, 2013: 188). Em uma entrevista concedida a La Estafeta Literaria, Carmen Laforet declarou acerca da protagonista de Nada (1945): "No; no soy Andrea ni tengo nada que ver con ninguno de mis personajes. Me siento totalmente desligada de ellos. Los he creado, pero los he dejado vivir libremente sin intentar imponerles mi voluntad" (Sumalla Benito, 2003: 147). Assim, em público, Carmen Laforet se desligava de suas personagens, buscando preservar sua identidade mais íntima. No entanto, em suas cartas pessoais, é possível perceber quão importantes eram suas vivências autobiográficas na criação de seus relatos narrativos (Martín Gutiérrez, 2018). 
Ainda que muitas autoras tenham sofrido a censura franquista, sendo impedidas de publicar suas obras, as que tiveram sucesso também sofreram com a exposição, chegando a abandonar, em muitos casos, a escrita. Conforme a escritora Elena Soriano, "no sólo la censura era más severa para las mujeres, sino que la opinión pública, los lectores y la crítica trataban de distinta manera a las mujeres" (Rodríguez, 2000: 48). Dessa forma, à menor tiragem de suas obras e ao maior desconhecimento de seus nomes nos círculos literários somou-se uma perseguição de gênero. No entanto, apesar da forte censura, algumas autoras não só transgrediram com seus temas a ordem estabelecida, mas também questionaram o papel da mulher subordinado aos valores católicos e ao modelo de feminilidade próprio do sistema ditatorial (Montejo Gurruchaga 2009). As escritoras Carmen Kurtz, Carmen Laforet e Elena Fortún denunciaram a discriminação das mulheres por meio da sua literatura.

Assim, no inseguro panorama cultural dos anos de 1940, houve tentativas muito dispersas de fazer uma literatura alheia aos postulados oficiais. Ángela Figuera Aymerich, escritora da poesia desarraigada, obteve uma avaliação favorável para publicar sua obra Toco la tierra letanías (1962), pela editora Rialp: "Nada fundamental que objetar a estas letanías poéticas", declarava o relatório do censor (AGA, 21/13774). No entanto, alguns anos antes, Ángela havia encontrado dificuldades para publicar suas duas primeiras obras, Mujeres de barro (1948) e Soria pura (1949), pelo erotismo que exalavam de suas letras, um aspecto que se somava ao fato de que a escritora havia sido destituída de sua vaga docente em razão de seus vínculos com a Segunda República.

No entanto, Nada (1945), novela da escritora Laforet, vencedora do Premio Nadal, foi capaz de levar uma mensagem realista e crítica aos leitores, apesar do vigilante olhar ditatorial do imediato pós-guerra. Por meio de uma voz feminina, Laforet descontrói a sociedade idealizada pela demagogia triunfalista do franquismo. 0 microcosmos da família da Rua de Aribau revela as sequelas da Guerra Civil Espanhola e o poder opressivo da ditadura. Como afirma Fraai (2003: 38), Nada foi um romance de grande importância para "muchas escritoras nacientes que tímidamente estaban tentando el vado dentro de los límites de lo permitido por la censura". No entanto, foi considerado, pelos censores, um romance "insulso, sin estilo ni valor literario alguno. Se reduce a describir cómo pasó un año en Barcelona en casa de sus tíos una chica universitaria. Sin peripecias de relieve. Creo que no hay inconveniente en su autorización" (AGA 21/07610). Uma avaliação excessivamente limitada do alcance que poderia ter - e que de fato teve - essa obra literária. Larraz (2014: 182) destaca que, ainda que a escritora tenha oferecido um panorama deprimente da Barcelona do pós-guerra, não incluiu, sabiamente, cenas eróticas, léxico que poderia ser visto como vulgar ou imoral, nem alusões diretamente políticas ou irreverências religiosas. Fez uso de um estilo direto e simples, sem 
incluir problemáticas explicitamente políticas que lhe pudessem trazer complicações, empregando, concomitantemente, um discurso de caráter testemunhal. Para uma censura que se atinha mais ao detalhe que à essência, que utilizava um critério extremamente minucioso em relação à religião e que exercia um puritanismo excessivo, Nada não parecia ser uma ameaça para o regime (Grecco, 2017).

As escritoras nos anos de 1940 e 1950 experimentaram um processo de enfrentamento para abrir passagem no mundo masculinizado das letras, sofrendo, além da discriminação legal do regime, críticas de seus companheiros de escrita e a censura oficial do franquismo (Montejo Gurruchaga, 2010). Para outras tantas escritoras, a censura mais importante chegou pela mão da autoimposição. Escritoras pouco conhecidas no panorama espanhol, como Eulalia Galvarriato, que havia sido finalista do Premio Nadal de 1946, e Luisa Forrellad, que levou o prêmio no ano de 1953, com sua obra Siempre en capilla (1954), abandonaram o mundo das letras confinadas à sombra da invisibilidade e à conformação de um projeto vital que se desenvolveu por outros caminhos. A outras, acrescentou-se à censura a repressão que viveram por motivos políticos ou ideológicos, seja pela própria condenação, como Rosa Chacel e María Teresa León, cuja militância política Ihes conduziu ao caminho do exílio, como de outras tantas apontadas como suspeitas em virtude de seus laços familiares, como Elena Fortún e Dolores Medio, cujos maridos foram exilados e condenados durante a Guerra Civil Espanhola (Martín Gutiérrez, 2018). Também Elena Soriano foi afastada de seu posto no magistério em razão de seu marido haver estado preso. A condenação dos homens trazia consigo a marginalização das mulheres de sua família. Dessa maneira, à censura própria do regime acrescentava-se então uma censura de gênero aplicada a todas aquelas mulheres cujos familiares houvessem estado relacionados política ou sindicalmente com a defesa da Segunda República, da mesma forma que ocorreu com a violência que vivenciaram os familiares vítimas da repressão franquista (Abad Buil, Heredia Urzaiz y Marías Cadenas, 2012). Muitas autoras que se atreveram a introduzir em seus relatos realidades que colocaram em debate os valores do catolicismo ou falangista, ressignificados pelo regime, sofreram com a temida caneta vermelha do censor.

Algumas escritoras contaram com aliados dentro do regime censor (Leggott, 2014). Outras, no entanto, não disfrutaram dessa proteção interna (Grecco, 2017) e sofreram a dura censura, como foi o caso de Ana María Matute, que viu sua obra Luciérnagas não autorizada em novembro de 1953 (AGA 21/10494). A escritora conseguiria posteriormente publicar essa obra narrativa sobre as vivências dos meninos após a brutalidade da guerra em 1955 sob o título En esta tierra, com os remendos que a censura lhe impôs em até três diferentes ocasiões. Seu relato cru e doloroso, ainda que não criticasse diretamente o regime, não superou a rigidez moral franquista. Nas palavras da escritora, que já no período democrático decidiu 
recuperar o manuscrito original e ocupar seu lugar na literatura, Luciérnagas " no es una novela política, sino que es humana, de jóvenes que no comprenden que han hecho ellos para merecer esto" (El País, 1993). Carmen Kurtz também teve que lidar com a mutilação que sofreu seu segundo romance, La vieja ley (1956), no qual criticava o modelo educativo imposto às mulheres, porém o retrato sobre a prostituição no pós-guerra foi desfigurado pela censura (Rodríguez-Moranta, 2018: 39). Kurtz havia sido agraciada com o Premio Ciudad Barcelona em 1955, pelo seu romance Duermen bajo las aguas (1955), que curiosamente havia conseguido passar pela ferrenha censura. A autocensura de Kurtz explica em parte que sua obra pudesse ser publicada, já que a autora evitou deliberadamente conceder detalhes acerca das consequências do duro pós-guerra (Rodríguez-Moranta, 2018: 42).

Um dos gêneros por excelência no qual as escritoras do imediato pós-guerra despontariam suas letras foi o romance. Muitas autoras, como as escritoras pró-franquistas Mercedes Fórmica e Concha Espina, tiveram seus romances premiados, ambas com 0 Prêmio Cid (1954) e o Prêmio Nacional de Novela Miguel de Cervantes (1949), respectivamente. No entanto, cabe ressaltar que nenhuma delas foi admitida na Real Academia Espanhola. Ainda que muitas viessem a receber prêmios e certo reconhecimento à sua escritura, outras não veriam editadas ou reeditadas suas obras até o fim da ditadura. Ángela Figueras Aymerich teve suas obras completas publicadas já no período democrático e após sua morte. Além disso, muitas escritoras, postas em segundo plano em relação aos escritores e condenadas ao exílio interior, serão invisíveis dentro da esfera das letras, publicando sem uma periodicidade estável e em editoras de menor prestígio (Montejo Gurruchaga, 2010). As mulheres passaram por uma difícil aceitação no panorama narrativo e editorial durante os primeiros anos do regime franquista, o que levou algumas delas, de poder aquisitivo mais alto, a editar suas próprias obras.

Muitas escritoras ainda utilizaram estratégias na construção do diálogo literário tentando escapar da censura. Assim, frequentemente tinham suficiente astúcia para fabricar (e disfarçar) sua palavra. Recorrendo a uma linguagem ambígua, inventaram táticas de camuflagem e dissimulação que tacitamente podiam levar a formas efetivas de críticas em relação ao regime sem que suas obras fossem retidas pelos censores. A escritora Eulalia Galvarriato conseguiu evitar a censura de sua obra narrativa Cinco sombras (1947) graças às funções que outorgou ao narrador, um homem mais velho com autoridade social, em detrimento da possivel escolha de uma personagem feminina que houvesse sido classificada como insubmissa ou despertado as suspeitas do leitor. Por intermédio de Diego, a voz em off em Cinco sombras, é possível perceber "la importancia del narrador principal intradiegético y la diégesis que presenta" (Kallin, 2013: 27), permitindo que, em sua voz, fossem expressadas as queixas 
das protagonistas femininas pela dor e a miséria do pós-guerra. A narrativa, situada em um tempo distante da Espanha dos anos de 1950, concedeu à autora certa liberdade para criticar indiretamente a sociedade franquista e demonstrar sua posição ideológica (Kallin, 2013: 26).

Elisabeth Mulder Pierluisi, nascida em Barcelona, em 1904, de mãe latino-americana e pai holandês, situou também muitas de suas obras escritas sob o franquismo em espaços geográficos fora da Espanha. Apesar disso, em 1941, sua obra Preludio a la muerte (1941) foi censurada ao narrar o suicídio de um de seus protagonistas. 0 censor recordou à escritora da Geração de 27 que "las mujeres españolas no se suicidaban", e Mulder foi obrigada a modificar o fim de sua obra para que fosse publicada. A protagonista, então, morreria acidentalmente na nova versão (Mañas Martínez 1988: 292). Assim, um considerável número de obras que atentaram contra a moral católica e os valores do regime foi marcado com a caneta vermelha do censor.

As escritoras sabiam que havia temas e vocábulos que não podiam ser utilizados, sendo comuns as substituições de palavras. Efetivamente, segundo Goytisolo (1978), "si algún mérito hay que reconocer a la censura es el de haber estimulado la búsqueda de las técnicas necesarias al escritor para burlarla e introducir de contrabando en su obra la ideología o temática prohibidas" (Camino Gutiérrez Lanza, 1997: 286). A escritora Elena Quiroga sofreu esse tipo de censura em Trayecto uno (1953), ao ter sua obra, ainda que não desautorizada, criticada: "literariamente emite algunas expresiones chabacanas" (AGA 21/10841). No entanto, em Humilladero, que posteriormente foi publicada com o título La última corrida (1958), pela editorial Noguer, embora tenha feito uso de "vocabulário vulgar", salvou-se da censura pela admiração que a literata parecia despertar no censor:

Novela donde la autora transcribe con talento más o menos vigoroso de la realidad una serie de estampas realista de nuestra "fiesta nacional", es decir de la torería. Es la novela de los toreros con ciertas limitaciones que voluntariamente se ha impuesto la escritora. En el curso de la narración cultiva de vez en cuando el vocabulario chabacano que ha aportado la nueva escuela — digamos nuev[b]a escuela en España, en Francia ya está pasada de moda — pero ello no constituye argumento contra la moral, ni el dogma, solamente contra el buen gusto. Pese a ello destaca en sus páginas el talento de esta escritora gallega. (AGA 21/11920)

Elena Soriano também viu sua obra Medea (1955) influenciada pela questão do vocabulário: "Tiene páginas fuertes pero puede permitirse su publicación" (AGA 21/11073). A moralidade da linguagem e os bons costumes também serviriam como pretexto para eliminar alguns trechos da obra Entre visillos (1957) e indicar a Carmen Martínez Gaite a obrigatoriedade da língua pura, limpa. A obra, mesmo mutilada, teve sua publicação autorizada pela editora Destino. 0 relatório do censor destacava que era uma 
historia provinciana de un grupo de chicas, sus estudios y sus amoríos. El argumento se encuentra en torno a la figura del nuevo profesor de alemán del sustituto, desde que llega al pueblo de las vacaciones de navidad. Convendría suprimir dos expresiones groseras en las páginas 41 y 64. Puede publicarse. (AGA 21/11921)

Outra das estratégias empregadas para driblar a censura foi a inserção de determinadas pessoas no processo editorial. Foi assim que Ángela Figuera Aymerich, que vinha incrementando em suas poesias críticas ao regime, teve publicada sua obra Belleza cruel em 1958, após enviar previamente um manuscrito a alguns conhecidos no México e que estes o levassem diretamente ao Premio de Poesía Nueva España. Ainda que a história da censura seja um registro de conflito e de tempos nebulosos em um terreno de constante transformação, no qual o censor se converte em colaborador de um sistema repressivo e o censurado na vítima desse procedimento, as escritoras criaram estratégias deliberadas para escapar da censura, fazendo uso de seu (limitado) poder para publicar suas obras.

Nesse contexto, as autoras estrangeiras também não escaparam da estrutura censora do franquismo. No pós-guerra, diversas obras que questionavam os valores do regime foram proibidas, entre elas as da pensadora Simone de Beauvoir, da teórica Betty Friedan ou da romancista e ensaísta Mary McCarthy. A obra O grupo, de McCarthy, não foi publicada na Espanha até 1976 (Godayol, 2017). No entanto, curiosamente, O segundo sexo e A mística feminina passaram pela censura, e, ainda mais insólito para o período, a falangista Mercedes Fórmica pôde realizar a primeira recensão de 0 segundo sexo na Espanha. 0 caso de Concha Espina também foi paradigmático. Antes do início da guerra civil, Espina já era uma literata consagrada, havia sido candidata ao Nobel e havia recebido, em 1927, o Prêmio Nacional de Literatura por seu trabalho Altar mayor (1926). Católica e conservadora, continuou escrevendo durante o regime franquista, mesmo depois de sua cegueira em 1940, até mesmo escreveu um poema em homenagem a José Antonio Primo de Rivera, fundador da Falange Española. Provavelmente, mais do que sua condição de apoiadora do regime, era o reconhecimento nacional e internacional que a autora já possuía que fez com que a censura fosse mais benévola com suas obras. Separada do marido, Ramón Gómez de la Serna, também escritor, Espina aproveitou a situação democrática dos anos de 1930 para solicitar o divórcio formal. Espina já havia denunciado em seu trabalho La virgen prudente (1929) as dificuldades das mulheres no mundo masculinizado das letras e do feminismo emergente. Durante o período pós-guerra, a narrativa sobre o papel político-social das mulheres como tema central em seu trabalho foi progressivamente sendo abandonada, uma época que coincidiu com sua incorporação na Seção Feminina da Falange. Porém continuou publicando em diferentes mídias, como a Rádio Nacional de Espanha, na qual já havia co- 
laborado em 1937, e na imprensa, especificamente no jornal conservador $A B C$ (Fernández Gallo, 2006; Bordonada, 2011).

Embora atuante, a função censora franquista encontrou, no decorrer de sua atividade, numerosos obstáculos perante os mecanismos de adaptação e resistência dessas autoras: algumas com mais poder, como as falangistas, que dispunham de recursos para negociar com as autoridades políticas; outras, com menos capital político, utilizaram com mais frequência estratégias discursivas cuja função consistia em criar novos significados que não fossem identificados pelos censores. Todas elas, no entanto, de alguma maneira, precisaram se camuflar e se violentar (usando pseudônimos ou evitando certos assuntos ou linguagens) para que pudessem ultrapassar as barreiras censoras sociais e oficiais.

\section{CONCLUSÕES}

$\mathrm{C}^{2}$

om a consolidação da ditadura, foram promulgadas regulamentações que condenavam as manifestações dissidentes ao interior do território espanhol, proibindo as liberdades fundamentais. A essa repressão e controle social seria acrescentada a implementação de novas políticas denominadas "de gênero", orientadas a transformar as identidades femininas no incipiente pós-guerra a fim de excluí-las discursivamente da dimensão pública. Nesse difícil contexto, algumas escritoras se animaram a seguir com suas criações literárias, apesar da instauração de uma ferrenha censura cada vez maior a partir de 1938. Algumas delas pertenciam a uma geração que havia feito uso de sua pluma nos anos prévios à Guerra Civil Espanhola e compartilhado espaços sociais com outras escritoras que tiveram de partir ao exilio. Também nessa etapa de pós-guerra, consagraram-se algumas autoras pertencentes a gerações posteriores que haviam alcançado certa projeção no mundo das letras. Em qualquer caso, suas palavras foram, por um lado, um exercício de desobediência a um regime que pretendia condená-las à invisibilidade, e, por outro, uma estratégia de sobrevivência dentro do difícil panorama da escrita dos anos de 1940.

Entre as formas encontradas pelas autoras para burlar a caneta vermelha, temos a autocensura, na qual foram evitados principalmente temas considerados polêmicos pelos censores. Outra maneira de escapar seria mediante o uso de um pseudônimo que ajudava a diluir sua identidade como autoras. Apesar dessas estratégias conscientes, figuras como Carmen Martín Gaite e Ana María Matute não conseguiram, em certas ocasiões, a autorização necessária para a difusão de algumas de suas obras de maior destaque durante esse período. Nesta pesquisa, também foi pretensão incluir as escritoras de tendências afins ao regime, como as falangistas Mercedes Fórmica e Concha Espina. Muitas escritoras pró-regime gozaram de certa liberdade graças ao prestígio que alcançaram nos círculos intelectuais falangistas ou de apoiadores do regime. 
Em qualquer dos casos, a censura esteve orientada ao controle da moral sustentada nos valores tradicionais e católicos. Os temas e os personagens que os censores avaliavam deveriam confirmar esses valores e desenvolver sua história segundo os códigos de consenso social enunciados pelo novo regime. A sexualidade e o erotismo, especialmente nas mulheres, eram duramente castigados pelo censor. As mortes "não naturais", como o aborto ou o suicídio, foram também fatos narrativos que não escaparam da estrita censura franquista, como ocorreu com a obra de Mulder Pierluisi. No entanto, em certas ocasiões, foi possível que as mulheres vissem suas obras publicadas até mesmo quando se aproximavam de forma arriscada a fatos, personagens ou narrativas censuráveis pelo regime, porque foram "desprezadas" em suas habilidades pelos censores homens. Em contrapartida, o prestígio que tinha a literatura apresentada a prêmios ou a concursos literários garantiram a publicação de criações como Nada, de Carmen Laforet, ou a obra de Ángela Figuera Aymerich, intitulada Belleza cruel, que continha trechos eróticos.

A incorporação do olhar de gênero no estudo da censura prévia permite visibilizar não apenas escritoras mais desconhecidas, como Eulalia Galvarriato, mas também revela a atuação política das mulheres, que se fizeram presentes à sombra no panorama literário do pós-guerra. As autoras experienciaram na própria carne uma censura generalizada ao serem excluídas dos círculos literários mais prestigiosos. Além disso, o receio de serem apontadas como transgressoras, e por isso perseguidas, fez que muitas decidissem abandonar sua ocupação ou que até negassem sua identidade literária com o uso de um pseudônimo. Ainda que o regime franquista buscasse dilacerar a capacidade de expressão dessas mulheres escritoras, isso não significa que estas estivessem ausentes no mundo das letras, como se discutiu nestas páginas. Assim, 0 imaginário do patriarcado colaborou para a construção de uma outreidade de autoria feminina desprovida de códigos de sucesso, idoneidade, criatividade e inteligência, uma identidade autoral que, como contraponto, só podia ser masculina. Esse imaginário foi sobre o qual se edificou o menosprezo dos homens intelectuais e censores em relação às escritoras, em uma tentativa de silenciá-las. No entanto, as mulheres criadoras resistiram à sua exclusão no campo cultural e lutaram pelo reconhecimento da autoridade cultural feminina (Pérez Fontdevila e Torras Francès, 2019). Como observou Capdevila-Argüelles (2017: 41), "el silencio no es lo mismo que la ausencia. Ellas siempre han estado ahí".

\section{NOTAS}

1 Sobre a Seção Feminina da Falange Espanhola, sugerimos a leitura de Begoña Barrera (2019).

2 Rama feminina da Associação Católica Espanhola fundada na década de 1920 com o pretexto de criar uma mobilização social antimoderna, cumprindo o papel de transmissoras do 
modelo ideal de mulher católica que encontrava estreitas relações com o arquétipo feminino promovido pelo regime de Francisco Franco.

3 Esclarecimento: na verdade, Elena Quiroga nasceu em Santander, Espanha.

\section{REFERÊNCIAS BIBLIOGRÁFICAS}

ABAD BUIL, I.; HEREDIA URZAIZ, I.; MARÍAS CADENAS, S. Castigos "de género" y violencia política en la España de posguerra. Hacia un concepto de "represión sexuada" sobre las mujeres republicanas. In: IBARRA AGUIRREGABIRIA, A. (coord.). No es país para jóvenes. Actas del III Encuentro de Jóvenes Investigadores en la HC (Granada, 2009). Araba: Instituto Valentín de Foronda, 2012. p. 1-18.

AGA — Arquivo General de la Administración. Seção Cultural: código 21/07610. Alcalá de Henares: AGA.

. Seção Cultural: código 21/10494. Alcalá de Henares: AGA.

Seção Cultural: código 21/10841. Alcalá de Henares: AGA.

. Seção Cultural: código 21/11073. Alcalá de Henares: AGA.

. Seção Cultural: código 21/11920. Alcalá de Henares: AGA.

. Seção Cultural: código 21/11921. Alcalá de Henares: AGA.

. Seção Cultural: código 21/13774. Alcalá de Henares: AGA.

AMADOR, P.; RUIZ FRANCO, R. (eds.). La otra dictadura: el régimen franquista y las mujeres. Madrid: Universidad Carlos III, 2007.

ALÍA MIRANDA, F.; BASCUÑÁN AÑOVER, Ó.; VICENTE RODRÍGUEZ-BORLADO, H.; VILLALTA LUNA, A. M. Mujeres solas en la posguerra española (1939-1949). Estrategias frente al hambre y la represión. Revista de Historiografía, Madrid, año XIV, n. 26, p. 213-236, 2017. https://doi.org/10.20318/revhisto.2017.3706.

ARCE PINEDO, R. La construcción social de la mujer por el catolicismo y las derechas españolas en la época contemporánea. 2016. Tesis (Doctoral), Universidad de Cantabria, Santander, 2016.

BARRERA, B. La Sección Femenina 1934-1977. Historia de una tutela emocional. Madrid: Alianza Editorial, 2019.

BLASCO HERRANZ, I. Las mujeres de la Sección Femenina de Falange: sumisión, poder y autonomía. In: SEGURA GRAíNOO, C.; CERREDA JIMÉNEZ, A. I. Las mujeres y el poder: representaciones y prácticas de vida. VII Coloquio de AEIHM. Madrid: Editora Al-Mudayna y Aeihm, 2000. p. 253-268.

. Paradojas de la ortodoxia. Zaragoza: Servicio de Publicaciones de la Universidad de Zaragoza, 2003.

. Introducción del Dossier Mujeres y Religiones. Desafíos para el feminismo actual. Clepsydra: Revista Internacional de Estudios de Género y Teoría Feminista, Santa Cruz de Tenerife, v. 9, p. 11-17, 2010.

. Género y nación bajo el franquismo. In: MICHONNEAU, S.; NÚÑEZ SEIXAS, X. M. (eds.). Imaginarios

y representaciones de España durante el franquismo. Madrid: Casa de Velázquez, 2014. p. 49-72.

. (ed.). Mujeres, hombres y catolicismo en la España contemporánea. Nuevas visiones desde la historia. Valencia: Tirant lo Blanch, 2018. 
BORDONADA, Á. E. Escritoras republicanas y escritoras franquistas dos visiones de la guerra civil. In: MAYORAL, M.; MAÑAS MARTíNEZ, M. M. Memoria de la guerra civil en las escritoras españolas. Madrid: Sial, 2011.p. 13-52.

BOURDIEU, P. O poder simbólico. Rio de Janeiro: Bertrand Brasil, 2010.

CABRERO, C. Mujeres contra el franquismo. Asturias (1937-1952). Oviedo: KRK, 2006.

CAPDEVILA-ARGÜELLES, N. Autoras inciertas. Madrid: Sílex, 2017.

CENARRO LAGUNAS, Á. La sonrisa de Falange: auxilio social en la guerra civil y en la posguerra. Barcelona: Crítica, 2006.

CHAUDHURI, N. et al. Contesting archives: finding women in the sources. Illinois: University of Illinois, 2010.

CHULIÁ RODRIGO, E. La evolución silenciosa de las dictaduras. El régimen de Franco ante la prensa y el periodismo. Madrid: Instituto Juan March de Estudios e Investigaciones, 1997. p. 144-145.

DE LA GUARDIA, C. La violencia del nombre. Mujeres, seudónimos y silencios. In: JORNADAS INTERESCUELAS/ DEPARTAMENTOS DE HISTORIA, 11., 2007, San Miguel de Tucumán. Anales [...]. San Miguel de Tucumán: Universidad de Tucumán, 2007. p. 1-15.

CAMINO GUTIÉRREZ LANZA, M. Leyes y criterios de censura en la España franquista: traducción y recepción de textos literarios. In: VEGA, M. Á.; MARTÍN-GAITERO, R. (eds.). La palabra vertida. Investigaciones en torno a la traducción. Madrid: Editorial Complutense, 1997. p. 283-290.

DALY, M. Gyn/ecology: he metaethics of radical feminism. Boston: Beacon Press, 1978.

DE DIOS FERNÁNDEZ, E. Domesticidad y familia: ambigüedad y contradicción en los modelos de feminidad en el franquismo. Feminismo/s, Alicante, n. 23, p. 23-46, 2014. http://dx.doi.org/10.14198/fem.2014.23.02.

DI FEBO, G.; SABA, M. La condición de la mujer y el papel de la Iglesia en la Italia fascista y la España franquista: ideología, leyes y asociaciones femeninas. In: GARCÍA-NIETO, M. C. (ed.). Ordenamiento jurídico y realidad social de las mujeres. Madrid: Universidad Autónoma de Madrid, Seminario de Estudios de la Mujer, 1986. p. 439-452.

DI FEBO, G. La cuna, la cruz y la bandera. Primer franquismo y modelos de género. In: MORANT, I. (dir.). Historia de las mujeres en España y América Latina. Del siglo XX a los umbrales del XXI. Madrid: Cátedra, 2006. v. IV, p. 217-237.

EL PAíS. Entrevista a Ana María Matute. Madrid, 26 oct. 1993. Edición regional de Barcelona.

ENDERS, V. L.; RADCLIFF, P. B. (eds.). Constructing Spanish womanhood. Female identity in modern Spain. Nueva York: University of New York, 1998.

FRAAl, J. Rebeldías camufladas: análisis de tres novelas femeninas de los años cuarenta en España. Alcalá de Henares: Concejalía de Mujer del Ayuntamiento de Alcalá de Henares, 2003.

FERNÁNDEZ GALLO, C. Concha Espina: narrativa extensa de una novelista que quiso ser poeta. Madrid: Universidad Nacional de Educación a Distancia, 2006.

GODAYOL, P. Tres escritoras censuradas. Simone de Beauvoir, Betty Friedan y Mary McCarthy. Granada: Comares, 2017. 
GOYTISOLO, J. Los escritores españoles frente al toro de la censura. Madrid: Aguilar, 1978, p. 845-846. (Obras completas I).

GRECCO, G. L. El control del libro durante el primer franquismo. Diálogos, Maringá, v. 18, n. 1, p. 361-380, 2014. https://doi.org/10.4025/dialogos.v18i1.35957.

. De la pluma como oficio a la pluma oficial: Estado y literatura durante los "nuevos estados" de Getulio Vargas y Francisco Franco (1936-1945). 2017. Tesis (Doctoral), Universidad Autónoma de Madrid, Madrid, 2017.

JAIME DE PABLOS, M. E. Remaking the literary canon in English: women writers, 1880-1920. Granada: Editorial Comares, 2018.

JESUS, C. M. Diario de Bitita. Rio de Janeiro: Nova Fronteira, 2007.

KALLIN, M. La función de los narradores en Cinco sombras de Eulalia Galvarriato. 2013. Tesis (Licenciatura), Universidad Linneo, Suecia, 2013.

LARRAZ, F. Letricidio español. Censura y novela durante el franquismo. Gijón: Ediciones Trea, 2014.

LEGGOTT, S. Negotiating censorship in the postwar spanish novel divorce and civil marriage in Elena Quiroga's Algo pasa en la calle (1954). Revista de Escritoras Ibéricas, Madrid, v. 2, p. 121-144, 2014. https://doi. org/10.5944/rei.vol.2.2014.12949.

LEGGOTT, S. Las novelas de posguerra de Elena Quiroga (1921-1995). Revista Internacional de Estudios Literarios y Humanisticos, United States, v. 5, n. 2, p. 13-20, 2017. 10.18848/2471-8602/CGP/v05i02/1320.

LOTMAN, M. L. El arte canónico como paradoja informacional. Criterios - Revista Internacional de Teoría de la Literatura y las Artes, Estética y Cultorología, S.I., v. 2, n. 30, p. 23-29, 1993.

MAINER, J.-C. Tramas, libros, nombres: para entender la literatura española, 1944-2000. Barcelona: Anagrama, 2005.

MAÑAS MARTínEZ, M. M. La obra narrativa de Elisabeth Mulder. 1988. Tesis (Doctoral), Universidad Complutense de Madrid, Madrid, 1988.

MARÍN-MARÍN, V. Carmen Laforet: una mujer en fuga. Rilce - Revista de Filología Hispánica, Pamplona, v. 29, n. 1, p. 187-189, 2013.

MARTÍN GUTIÉRREZ, S. Obreras y católicas. De la formación a la movilización. Roles de género y compromiso temporal de la Hermandad Obrera de Acción Católica Femenina (HOACF) en España (1946-1970). Madrid: Universidad Complutense de Madrid, 2017.

- Letras hacia la libertad. Intimidad, subjetividad y anhelos en la correspondencia de las escritoras Elena Fortún y Carmen Laforet (1947-1952). Travessias, Cascavel, v. 12, n. 1, p. 77-95, 2018.

McGEE DEUTSCH, S. Las derechas: the extreme right in Argentina, Brazil, and Chile 1890-1939. Stanford: Stanford University Press, 1999.

MONTEJO GURRUCHAGA, L. Escritoras españolas de posguerra: reflexión y denuncia de roles de género. Foro Hispánico: Revista Hispánica de Flandes y Holanda, Lovaina, n. 34, p. 187-205, 2009. 
Discurso de autora: género y censura en la narrativa española de posguerra. Madrid: Servicio de Publicaciones de la UNED, 2010.

MORANT i ARIÑO, T. Para influir en la vida del estado futuro: discurso — y práctica — falangista sobre el papel de la mujer y la feminidad, 1933-1945. Historia y Política, Madrid, n. 27, p. 113-141, 2012.

NICOLÁS MARÍN, M. E. La libertad encadenada. España en la dictadura franquista 1939-1975. Madrid: Alianza Editorial, 2005.

NICOLÁS MARÍN, M. E.; LÓPEZ GARCÍA, B. La situación de la mujer a través de los movimientos de apostolado seglar. La contribución a la legitimación del franquismo, 1936-1956". In: CAPEL MARTíNEZ, R. M. (coord.). Mujer y sociedad en España (1700-1975). Madrid: Ministerio de Cultura, 1982. p. 365-390.

ORTIZ HERAS, M. Mujer y dictadura franquista. Aposta - Revista de Ciencias Sociales, Madrid, n. 28, p. 1-26, 2006.

PÉREZ FONTDEVILA, A.; TORRAS FRANCÈS, M. (eds.). ¿Qué es una autora? Encrucijadas entre género y autoría. Barcelona: Icaria, 2019.

PÉREZ DEL PUERTO, Á. Más allá de las naciones. La defensa de la feminidad católica a través del proyecto educativo de Acción Católica en España y Estados Unidos (1940-1950). 2015. Tesis (Doctoral), Universidad Autónoma de Madrid, Madrid, 2015.

PRIETO BORREGO, L. (ed.). Encuadramiento femenino, socialización y cultura en el franquismo. Málaga: CEDMA, 2010.

RODRÍGUEZ, M. P. Vidas im/propias. Transformaciones del sujeto femenino en la narrativa española contemporánea. United States of America: Purdue Research Foundation, 2000.

RODRÍGUEZ-MORANTA, I. Duermen bajo las aguas (1955), de Carmen Kurtz: entre la autocensura y el asomo de una voz crítica en la posguerra española. Lectura y signo, León, n. 13, p. 35-56, 2018. http://dx.doi. org/10.18002/lys.v0i13.5666.

RUIZ FRANCO, R. ¿Eternas menores? Las mujeres en el franquismo. Madrid: Biblioteca Nueva, 2007.

SAID, E. Cultura e imperialismo. São Paulo: Companhia das Letras, 2005.

SPENDER, D. Man made language. Londres: Routledge, 1982.

SUMALLA BENITO, A. La novela de formación en la narrativa española contemporánea escrita por mujeres. 2013. Tesis (Doctoral), Universitat de Barcelona, Barcelona, 2013.

URBÁN FERNÁNDEZ, F. La calificación moral de las novelas en los años cincuenta. Cauce, Madrid, n. 2, p. 357-374, 1979.

VASALLO, J.; DE PAZ-TRUEBA, Y.; CALDO, P. (coords.). Género y documentación. Relecturas sobre fuentes y archivos. Córdoba: Editorial Brujas, 2016. (Colección Los mundos de Ayer).

YANAGISAKO, S. Mixed metaphors: native and anthorpological models of gender and kinship domains. In: COLLIER, J.; YANAGISAKO, S. (eds.). Gender and Kinship: essays towards a unified analysis. Standfor: Standfor University Press, 1987. p. 3-24. 